\title{
Genus Hyloconis new to China, with descriptions of two new species (Lepidoptera: Gracillariidae, Lithocolletinae)
}

\author{
Haiyan Bai \& Houhun Li*
}

Bai, H. \& Li, H. 2012: Genus Hyloconis new to China, with descriptions of two
new species (Lepidoptera: Gracillariidae, Lithocolletinae). - Entomol. Fennica 23: $227-230$.

The genus Hyloconis Kumata is for the first time recorded in China. Hyloconis bicruris sp. n. and H. luminata sp. n. are described. Generic characters are amended based on the Chinese material. Photographs of adults, illustration of genital structures and wing venation are provided, along with a key to all the known species.

H. Bai, College of Life Sciences, Nankai University, Tianjin 300071, China \& 2. Department of Bioscience and Biotechnology, Changzhi College, Changzhi, Shanxi 046011, China; E-mail: haiyanbai@163.com

H. Li (*Corresponding author), College of Life Sciences, Nankai University, Tianjin 300071, China; E-mail: lihouhun@nankai.edu.cn

Received 15 February 2012, accepted 17 June 2012

\section{Introduction}

The genus Hyloconis included four species when it was erected by Kumata in 1963 based on Japanese specimens. Noreika (1994) subsequently transferred Lithocolletis improvisella Ermolaev, 1986 to Hyloconis. Since then no further study has been carried out on this genus in the world. In the present paper, we record this genus in China for the first time and describe two new species, with amendment of generic characters based on the study of the Chinese material. Type specimens are deposited in the Insect Collection, College of Life Sciences, Nankai University (NKUM), Tianjin, and the Zoological Museum, Department of Bioscience and Biotechnology, Changzhi College (ZMCZC), Changzhi, Shanxi, China.

\section{Genus Hyloconis}

Hyloconis Kumata, 1963: 28.

Generic characters. Vertex tufted; antenna as long as forewing, with pecten on scape; labial palpus drooping, third segment about two times length of second. Forewing with veins $\mathrm{CuA}, \mathrm{M}_{2}$, $\mathrm{M}_{3}$ and $\mathrm{R}_{1}$ absent, $\mathrm{R}_{2} \sim \mathrm{R}_{5}$ remote at base, $\mathrm{R}_{5}$ from apex of cell to costa, $M_{1}$ from apex of cell to termen, $\mathrm{CuP}$ from lower angle of cell, 1A rudimentary, 2A simple. Hindwing with cell open; $M_{3}$ and $\mathrm{CuA}$ absent, $\mathrm{M}_{1}$ stalked with $\mathrm{M}_{2}, \mathrm{CuP}$ simple, A rudimentary.

Male genitalia with tegumen bearing more than four apical setae; costa with an ovate knob at base; transtilla incomplete; saccus with a process from middle of anterior margin; anellus often sclerotized, smooth, without setose lobes; eighth sternite produced caudally in flap shape. Female genitalia with sclerotized genital plate; ductus bursae sclerotized at least at base and signum present or absent.

Biology. Known larvae mine leaves of Leguminosae (De Prins \& De Prins 2010).

Diagnosis. Hyloconis is similar to Cremastobombycia Braun, 1908 in the presence of vein $\mathrm{R}_{2}$ in the forewing and the tegumen with more than four apical setae in the male genitalia, but can be 
easily distinguished by the transtilla separated medially, which is joined in the latter genus.

Remarks. According to Kumata (1963), the ninth sternite produced into a fairly wide flap, but it should be the eighth sternite based on our study and Kumata (1993); the number of apical setae on tegumen is an important character to distinguish genera in Lithocolletinae, which was not stated by Kumata. We also illustrated the venation of Hyloconis for the first time.

\section{Descriptions of new species}

\subsection{Hyloconis bicruris sp. n. Figs. 1a, 2a}

Type material. Holotype. $\hat{O}^{1}$, China, Kangding County $\left(30^{\circ} 04 \mathrm{~N}, 101^{\circ} 57 \mathrm{E}\right)$, Sichuan Province, 2,400 m, 8.VII.2001, leg. Houhun Li \& Xinpu Wang, genitalia slide No. BHY08130 (NKUM).

Description. Adult. Male (Fig. 1a). Forewing length $4.0 \mathrm{~mm}$. Head and tuft shining silvery brown. Labial palpus off-white on inner surface, brown on outer surface. Antenna fuscous except flagellum white on distal ten segments. Thorax and tegula bright silvery brown. Forewing golden brown; costa with a fuscous speck at base, with a bar-shaped silvery white speck near apex; silvery white specks at costal and dorsal 1/4, 1/2 and 3/4 respectively, edged with fuscous; cilia dark brown. Hindwing and cilia dark brown. Legs dominantly shining fuscous; fore tibia with two off-white specks dorsally, fore tarsi with three off-white specks, last segment off-white; tibia and tarsi of mid leg with two off-white specks respectively; hind femur on outer surface of distal part and hind tibia on basal 1/3 off-white. Abdomen fuscous.

Male genitalia (Fig. 2a). Tegumen with distal half sclerotized in bar shape. Valva broad at base, narrowed to $2 / 3$, then broadened gradually to apex, densely covered with long setae on inner surface; distal 1/4 bifurcate, forming two branches: dorsal branch rounded at apex, slightly shorter on left valva than on right; ventral branch longer than dorsal one, narrowed to apex (broken terminally); costa slightly arched near base; sacculus nearly triangular, wide and broad, occupying basal 1/5 length of valva, pointed at apex. Anellus membranous. Saccus subrectangular,
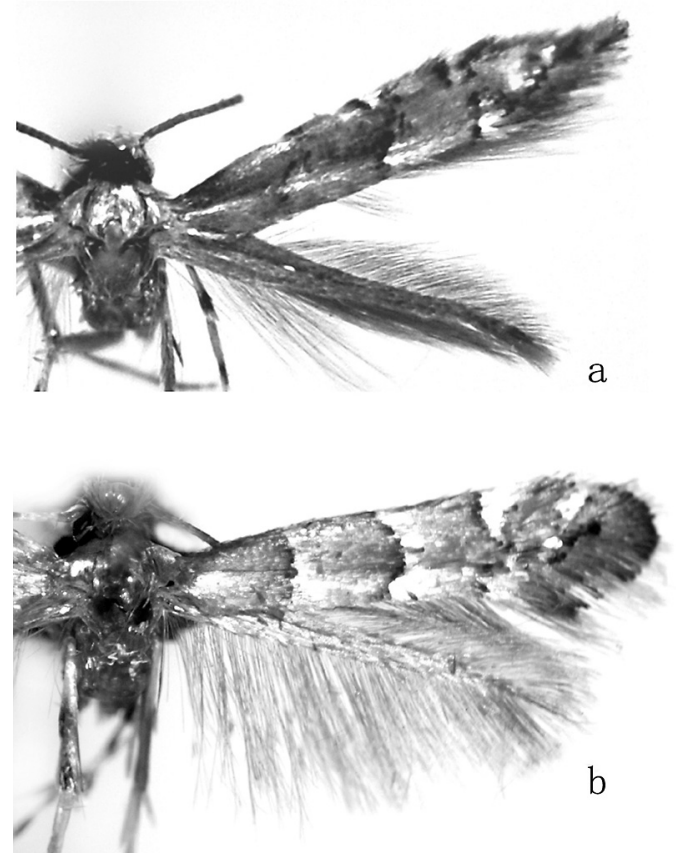

Fig. 1. Adults. - a. Hyloconis bicruris sp. n. - b. H. luminata sp. $\mathbf{n}$.

with semicircular excavation on anterior margin; median process about $1 / 3$ length of valva, barshaped, dilated distally. Phallus about 3/5 length of valva, bifurcate distally; cornutus absent. Eighth sternite broad triangular, narrowed gradually to pointed apex.

Female. Unknown.

Hostplant. Unknown.

Distribution. China (Sichuan).

Etymology. The species name is derived from the Latin word bicruris, meaning bifurcate, referring to the forked valva in the male genitalia.

Remarks. It is easy to distinguish $H$. bicruris sp. n. from other members of the genus by both valva and phallus bifurcate distally in the male genitalia.

\subsection{Hyloconis luminata sp. n. (Figs. 1b, 2b, 3)}

Type material. Holotype. ふ઼, China, Mt. Xiantai, Jingxing County $\left(38^{\circ} 01 \mathrm{~N}, 114^{\circ} 01 \mathrm{E}\right)$, Hebei Province, 1,200 m, 24.VII.2000, leg. Haili Yu, genitalia slide No. BHY08129 (NKUM). Paratypes. $2 \widehat{\delta}$, China, Peiking Agricultural University, 9.V.1956, leg. Jikun Yang, genitalia slide No. 



Fig. 2. Male genitalia. - a. Hyloconis bicruris sp. $\mathbf{n}$. - b. H. luminata sp. $\mathbf{n}$.

BHY09043, BHY09044 (NKUM); 1 §, China, Xizhashui Lingchuan County $\left(35^{\circ} 46 \mathrm{~N}, 113^{\circ} 18\right.$ E), Shanxi Province, 15.VII.2010, leg. Haiyan Bai \& Linlin Yang; $1{ }^{\top}$, China, Manghe $\left(35^{\circ} 29\right.$ N, $112^{\circ} 25$ E), Shanxi Province, 604 m, 5.VIII. 2011, leg. Haiyan Bai \& Jun Tie, genitalia slide No. B10024, B10065 (ZMCZC).

Description. Adult. Male (Figs. 1b, 3). Forewing length $3.0 \mathrm{~mm}$. Head shining silvery grey, with brown tuft. Labial palpus pale ochreous yellow. Antenna ochreous yellow, scape and pecten brown; flagellum ringed with fuscous except distal nine segments white. Thorax and tegula golden brown. Forewing brownish yellow, with shining golden lustre; markings white edged with black along inner margin: silvery white fascia at basal $1 / 4$ and middle respectively, the latter slightly arched outward; triangular silvery white

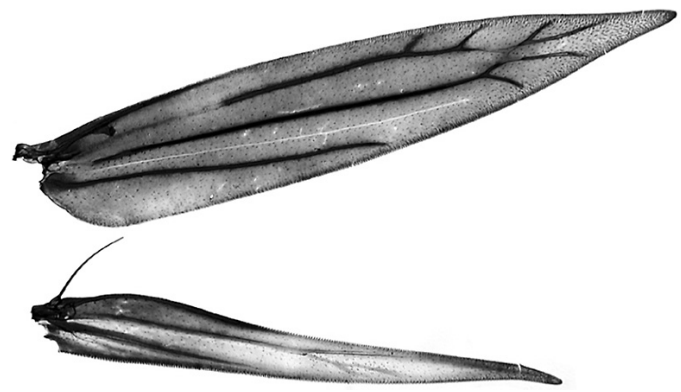

Fig. 3. Venation of Hyloconis luminata sp. $\mathbf{n}$.

specks at costal and dorsal 3/4 respectively; costa with a bar-shaped silvery white apical speck obliquely inward and across $2 / 3$ of wing; termen edged with black scales; cilia white mixed with pale khaki along apex and termen, brown on dorsum. Hindwing and cilia brown. Fore- and midlegs pale ochreous yellow except tibiae brown with three pale ochreous yellow specks dorsally, tarsi fuscous with two white rings except last segment white; hind leg pale yellowish, femur with basal half pale brownish on outer surface, tibia with distal $2 / 3$ brown, tarsi with three fuscous specks. Abdomen dark grey.

Male genitalia (Fig. 2b). Tegumen membranous in distal $1 / 4$. Valva wide at base, narrowed medially, with ovate dilation in distal $1 / 3$, ventral margin curved medially; inner surface with a sclerotized flap-shaped process on basal half, distal 2/3 with dense long setae; sacculus nearly broad triangular, occupying basal $1 / 3$ length of valva, rounded at apex. Saccus subrectangular, with deep semicircular excavation on anterior margin; median process bar-shaped, about 3/5 length of valva. Anellus sclerotized, tubular, about $1 / 5$ length of valva. Phallus about 1.2 times length of valva, tapering to apex; without cornutus. Eighth sternite produced triangularly to rounded apex.

Female. Unknown.

Hostplant. Unknown.

Distribution. China (Beijing, Hebei, Shanxi).

Etymology. The species name is derived from the Latin word luminatus, meaning shiny, in reference to the forewing with shining golden lustre.

Remarks. Hyloconis luminata $\mathbf{s p .} \mathbf{n}$. is similar to $H$. desmodii Kumata, 1963 in the subrectangular saccus with a bar-shaped process from middle of anterior margin, the sclerotized 
tubular anellus and the valva curved ventromedially in the male genitalia. It is distinguishable from the latter by the valva having a sclerotized flap-shaped process on basal half, an ovate dilation on distal $1 / 3$, and the phallus without any processes on outer wall. In $H$. desmodii Kumata, the valva has no process on inner surface, its distal $2 / 3$ is comparatively uniform in width and the phallus has two minute processes near apex.

\section{Key to the species of Hyloconis Kumata}

1. Forewing with whitish medio-basal streak; male genitalia asymmetrical (Kumata 1963: Fig. 16)

H. wisteriae

- Forewing without whitish medio-basal streak; male genitalia symmetrical or asymmetrical

2. Male genitalia with valvae asymmetrical (Fig. 2a)

H. bicruris sp. $\mathbf{n}$.

- Male genitalia with valvae symmetrical 3

3. Costa of valva with a triangular process near base

- Costa of valva without triangular process 5

4. Forewing with a black speck at base of costa, with a longitudinal whitish linear streak on distal $2 / 5$ of discal area

H. puerariae

- Forewing lacking markings as above

\section{H. improvisella}

5. Valva with ovate dilation in distal $1 / 3$ (Fig. 2b) H. luminata sp. n.

- Valva not dilated distally

6. Phallus with a pair of triangular lobes (Kumata 1963:Fig. 15) H.lespedezae

- Phallus without triangular lobes (Kumata 1963: Fig. 14)

H. desmodii

Acknowledgements. This study was supported by the National Natural Science Foundation of China (No. 30930014) and by the Natural Science Foundation of Shanxi Province, China (No. 2011011033-3).

\section{References}

De Prins, J. \& De Prins, W. 2010: Global taxonomic database of Gracillariidae (Lepidoptera). World wide web electronic publication (http://www.gracillariidae.net. Accessed in December 2011).

Ermolaev, V. P. 1986: New and little known species of leafblotch miners (Lepidoptera, Gracillariidae) from the south of the Primorye Territory. - Entomologicheskoe Obozrenie 65(4): 741-752.

Kumata, T. 1963: Taxonomic studies on the Lithocolletinae of Japan (Lepidoptera: Gracillariidae) Part II. Insecta Matsumurana 26(1): 1-48.

Kumata, T. 1993: A contribution to the knowledge of the Malaysian Lithocolletinae (Gracillariidae, Lepidoptera), with a revision of Indian Cameraria associated with Leguminosae. - Insecta Matsumurana, New Series 48: $1-85$.

Noreika, R. 1994: Two new species of Phyllonorycter Hübner, 1822 from the Far East area (Lepidoptera: Gracillariidae). — Phegea 22(3): 105-113. 